\title{
Laterality of lower limb amputation in diabetic patients: retrospective audit
}

\author{
Jonathan P Coxon, Ian W Gallen
}

Complications associated with diabetic patients' feet remain common and major problems for clinicians and patients. We conducted an audit after observing that lower limb amputations in diabetic patients who attended hospital seemed to occur more on the right side than on the left.

\section{Subjects, methods, and results}

We obtained information from the database of the Chiltern Diabetes Centre, which records the details of around 2000 diabetic patients attending hospital clinics in South Buckinghamshire. Patients' details are recorded on the computer system at each clinic visit.

For our audit, we extracted details from the database by setting up structured queries in the Microsoft Access program. Raw data consisted of one entry per patient. If a patient had more than one amputation, the level of the last amputation only was recorded. We excluded patients with bilateral amputations $(0.5 \%)$.

We performed $\chi^{2}$ tests (without continuity correction) to investigate any difference in laterality of amputation.

The table shows data for 1876 diabetic patients, $219(11.7 \%)$ of whom had had unilateral amputation. When we used $\chi^{2}$ tests to compare the sites of amputation between the left and right side, the differences between the two sides were highly significant for all levels.

\section{Comment}

We found a higher prevalence of right lower limb amputations in diabetic patients, regardless of the site of amputation. Estimates of the prevalence of amputation among diabetic patients vary considerably, with studies-usually population based-quoting between $1 \%$ and $7 \% .{ }^{1-3}$ In our study it was higher (11.7\%); there are two likely reasons. Firstly, our audit included amputations that were minor. Secondly, a higher prevalence of disease is to be expected as those patients who attend hospital usually have advanced disease. These reasons limit extrapolation of our results to all diabetic patients.

Our audit confirms a significant propensity for amputations of the right rather than the left lower limb in our cohort of diabetic patients. This applied to both types of diabetes.

An explanation for this finding must consider those factors that predispose to diabetic foot disease. The traditional triad of peripheral vascular disease, peripheral neuropathy, and infection is not entirely responsible as pressure loading on the sole of the foot, particularly callus formation, is believed to be important in diabetic foot disease.$^{45}$ Callus is thought to arise from a combination of dry skin (through autonomic neuropathy) and increased mechanical stresses.

Only physical stresses can account for the difference in laterality of amputation. If most people favoured their right foot during movement, especially in starting and stopping, more pressure would be applied cumulatively to that foot.

The clinical importance of this finding may be limited, but an awareness of the importance of mechanical strains on the foot may help to educate diabetic patients.

Contributors:JPC analysed the data, reviewed the literature, and wrote the paper. IWG set up the database and reviewed the final draft of the paper; he will act as guarantor for the paper.

Funding: None.

Competing interests: None declared.

1 Moss S, Klein R, Klein B. The prevalence and incidence of a lower extremity amputation in a diabetic population. Arch Intern Med 1992;152:610-6.

2 Lehto S, Romemaa T, Pyorala K, Laakso M. The risk factors predicting lower extremity amputation in patient with NIDDM. Diabetes Car 1996;19:607-12.

3 Reiber GE. The epidemiology of diabetic foot problems. Diabet Med 1996;13:6-11S

4 Ctercteko GC, Dhonendran M, Hutton WC, LeQuesne LP. Vertical forces acting on the feet of diabetic patients with neuropathic ulceration. $\mathrm{Br} J$ Surg 1981;68:608-14.

5 Veves A, Murray HJ, Young MJ, Boulton AJM. The risk of foot ulceration in diabetic patients with high foot pressure: a prospective study. Diabetologia 1992;35:660-3.

(Accepted 23 October 1998)
Chiltern Diabetes Centre, Wycombe Hospital, High Wycombe HP11 2TT

Jonathan P Coxon, house officer Ian W Gallen, consultant physician

Correspondence to: Dr Gallen iangallen@ compuserve.com

BMJ 1999;318:367

Differences in laterality of amputation in diabetic patients attending hospital clinics. Values are number (percentage) of patients unless stated otherwise

\begin{tabular}{|c|c|c|c|c|c|c|c|c|c|c|c|c|}
\hline \multirow{2}{*}{$\begin{array}{l}\text { Site of } \\
\text { amputation }\end{array}$} & \multicolumn{4}{|c|}{ All patients $(n=1876)$} & \multicolumn{4}{|c|}{ Patients with type 1 diabetes ( $n=1021$ ) } & \multicolumn{4}{|c|}{ Patients with type 2 diabetes ( $n=855$ ) } \\
\hline & Right & Left & $P$ value & $\chi^{2 \star}$ & Right & Left & $P$ value & $\chi^{2 \star}$ & Right & Left & $P$ value & $\chi^{2 \star}$ \\
\hline Toe & $80(4.3)$ & $19(1.0)$ & $<0.0001$ & $>25$ & $36(3.5)$ & $12(1.2)$ & 0.0005 & 12.0 & $44(5.1)$ & $7(0.8)$ & $<0.0001$ & $>25$ \\
\hline Partial foot & $48(2.6)$ & $10(0.5)$ & $<0.0001$ & $>25$ & $27(2.6)$ & $6(0.6)$ & 0.0003 & 13.3 & $21(2.5)$ & $4(0.5)$ & 0.0007 & $\overline{11.6}$ \\
\hline Below knee† & $51(2.7)$ & $11(0.6)$ & $<0.0001$ & $>25$ & $26(2.5)$ & $3(0.3)$ & $<0.0001$ & 18.2 & $25(2.9)$ & $8(0.9)$ & $<0.003$ & 8.8 \\
\hline All sites & 179 (9.5) & $40(2.1)$ & $<0.0001$ & $>25$ & $89(8.5)$ & $21(2.1)$ & $<0.0001$ & $>25$ & $90(2.2)$ & $19(2.2)$ & $<0.0001$ & $>25$ \\
\hline
\end{tabular}

${ }^{*} \mathrm{df}=3$.

†Includes amputations below and above knee level. 